\title{
HUELLAS DE SCHOPENHAUER EN LA NIVOLA DE UNAMUNO (SAN MANUEL BUENO, MÁRTIR)
}

\author{
Joaquín VERDÚ DE GREGORIO \\ Universidad de Ginebra
}

En todo trasfondo de la creación, tras el mito y la tragedia, ha fluido un camino interior por el que el ser humano ha pretendido captar el sentido del universo. La aparición de la filosofía subyace en el hombre que, desprovisto de su fábula y su cuento o desintegrado de ellos, comienza a preguntarse por su sentido. Por las cosas y el universo que le rodea. Y en el trasfondo de "su pregunta" siempre ha parecido translucirse una oscilación que se sitúa entre racionalismo - sobre todo a partir de Descartes y la física de Newton-e iluminismo. Y es que si el primero pretende of recer una claridad, unos límites comprensivos a través del concepto, la cuestión del iluminismo, en su claro nexo con el cansancio de la razón que comienza a perfilarse tras el Romanticismo, quiere mostrar aquellas fronteras que se ciernen sobre lo incomunicable, lo sensible y que llegará a integrar lo intuitivo.

Y dentro de esta última corriente - y más allá de Hegel y Kant- surge la fluencia del pensamiento de Schopenhauer, antecesor de ese pensamiento moderno que adquirirá sus más hondos reflejos en Nietzsche y Heidegger y en Bergson. En Unamuno y de honda manera en María Zambrano.

Hay una innovación en este pensador, influido por Platón, y el budismo, la filosofía oriental, a través de Las Upanishads.

Mas en lo inmediato, su obra esencial, El mundo como voluntad y representación, ha partido de la concepción kantiana que distingue entre fenómeno y cosa en sí, más otorgándole una diferente visión. Ya que para este filósofo el llamado fenómeno - lo conocido - equivale o supone la representación, lo que aparece en una primera visión, ese mundo que aparece en el primer despertar del hombre hacia lo 
que cree su sueño, creyendo que ese su sueño es lo real, lo conocido, en esa primera visión. Y que "toda comprensión es un acto de representación y queda como consecuencia, esencialmente en el terreno de la representación" (Schopenhauer 1992, pág. 194). Pero toda representación supone dos partes complementarias, sujeto y objeto, o sea, el que representa y lo representado. La representación parece ofrecer "el gran libro del mundo", un mundo que, a primera vista, es una visión que no podría ser comprendida sin el sujeto que la representa.

$Y$ es que esa representación o ese reflejo fluye, tantas veces, como el velo maya, ilusoria, encubierta... en una fusión-compresión entre sujeto y objeto; podría apaciguar el miedo a la muerte, el terror delante de la perspectiva de ser sajado de este mundo y que subsistiría tras la desaparición que supone la muerte. Y que ese "mundo del que la muerte nos separa no era sino mi representación". Y algo hallamos de la huella de Calderón de la Barca en este creador que tanto admira y cita a los clásicos españoles. Sería el suponer que el mundo es un sueño, un gran teatro, en él que el soñador es el creador.

Y, en otro aspecto, y en honda relación con la sintonía que pretendemos entre Schopenhauer y la obra de Unamuno - no decimos obras, por el limitado espacio de este estudio-San Manuel Bueno, mártir. Ya que el pueblo parece permanecer en su sueño de representación y "trascendencia". O al menos así lo anhela Don Manuel -San Manuel y más tarde su discípulo Lázaro.

Mas para el filósofo de la modernidad el mundo no es representación, sino voluntad - y ello podría relacionarse con la concepción de la cosa en sí de Kant, independiente de las formas de conocimiento. Si podemos pensarlas a través de nuestra razón, no podemos concebirlas. Esa voluntad, ese querer vivir $-\mathrm{y}$ recordemos la importancia y acepciones de la expresión querer en nuestra lengua- va más allá del ser humano, lo depasa. Es algo íntimo y desconocido cual fuerza o instancia metafísica o quizás cosmológica. Pues que surge como potencia anónima que actúa, a su vez, como potencia y como destrucción... rupturas, deseos de amor, deseo de nueva vida que en los amantes supone la reproducción de la vida. $Y$ en su envés, ello significa que el individuo como persona es ilusoria, sólo cuenta la especie.

Y es que la voluntad no se entronca tan sólo en el sujeto, lo depasa, lo desborda. Es un "elan" que se extiende más allá de él,

Fuera del hombre está la voluntad en todas partes, lo es todo, lo mismo la pesantez y la afinidad química que el instinto animal: todo tiende a algo, todo quiere. Solamente eso no tiende a nada. La voluntad nada quiere sino a sí misma. Carente de sentido y carente de fe, sería insensato enunciarla en el lenguaje de los valores. Todo lo que podemos hacer es explorar amargamente esa ciega potencia que impulsa, que se autodevora, ese ardor peligroso y destructor, $\mathrm{y}$, al no poder destruir, hemos de esforzarnos en adormecerla al máximo (Bangur 1984, pág. 206). 
Y enigmática aparece esa fuerza que ya no es fe, ni destino y que asemeja poseer las raíces del mundo, las causas de un extraño movimiento, ya que

en presencia del mundo, esa fuerza se irradia, se manifiesta como unidad del todo en abolición de las categorías espaciales, de lo exterior y de lo interior, de sí mismo y del prójimo. Sí, es ese querer el que anima a la naturaleza entera, y los antiguos panteismos son eternamente jóvenes, y los arcaicos animismos hallan su eco en el "homo sapiens". Y añade Schopenhauer, "soy yo la victima que sufre bajo la mano del verdugo que me castiga ferozmente, y yo soy también el que apiadado digno de piedad que, llorando sobre su víctima, llora sobre sí mismo" (Bangur, pág. 208).

El eco de estas palabras parecen resonar en las del protagonista de Unamuno -o quizás en él mismo- cuando el otro agonista le pregunta por su verdad. "La verdad, Lázaro, es acaso algo temible, algo intolerable, algo mortal; la gente sencilla no podría vivir con ella..." Esa verdad que tiene que expresar a Lázaro, el otro mundo social y científico... "Porque si no me atormentaría tanto, tanto, que acabaría gritándola en medio de la plaza, y eso jamás, jamás, jamás..." De ahí su necesidad de adormecerla para recrear a los otros en un sueño en el que no cree: "Yo estoy aquí para hacer vivir a las almas de mis feligreses, para hacerles felices, para hacerles que se sueñen inmortales y no para matarlos..." (Unamuno 1986, pag. 864).

Hay seres que no pueden o no soportarían el ver el otro lado del mundo, quizás atravesar ese dintel que significa el "velo maya" que supone la representación. Otros irán descubriendo la voluntad, trascendiéndola, que nunca negándola, mediante la contemplación, el arte, la compasión... e irán desentrañando y armonizando el dolor de la existencia.

Y es que esta voluntad reintegra al sujeto con su cuerpo para llegar a componer al individuo -individuum, no dividido. $\mathrm{Y}$ en este pasaje, tránsito desde el mundo de la representación al mundo de la voluntad, el ser inscribe su cuerpo en dos registros, hallando una cierta armonía, aunque tantas veces dolorosa.

El camino del ser como el de D. Manuel y Lázaro - fluye bajo la necesidad, quejas, muerte, y es que la voluntad surgiría como un deseo primario, que ni la sexualidad ni los bienes económicos, ni el poder podrían monopolizar... y esa tiranía del deseo se extiende incluso a los pensamientos, parece acunar un sentido absurdo de la existencia.

Pensar ociosos pensar para no hacer nada o pensar demasiado en lo que se ha hecho y no en lo que hay que hacer. A lo hecho, pecho, y a otra cosa que no hay, peor que remordimiento sin enmienda ¡Hacer! ¡Hacer! Bien comprendí yo ya desde entonces que Don Manuel huía [nos dice la narradora] de pensar ocioso y a solas, que algún pensamiento le perseguía (854).

Se trasciende toda ordenación racional o causal del mundo... mas, a su vez, los subterráneos de ese mismo mundo parten de nuestro propio interior y no hay 
una unidad - que podría suponer el alma - cuando la voluntad supone dilatación del ser más allá de sus limites; y la dispersión tampoco aparece como Dios, pues quizás como tal dispersión es diabólica - y en este aspecto hallaríamos la importancia de lo demoníaco en los escritores Georges Bernanos y Fedor Dostoyewski y sería interesante hallar las interrelaciones entre estos autores y la obra de Unamuno. $\mathrm{Y}$ es que en esa intimidad rota a veces, sólo a veces, Don Manuel, introduce en su universo un sentido de lo trágico, una tensión agónica entre su palabra hacia el pueblo - representación - y esa voluntad que le arrastra, mas cuyo destino desconoce... Pero más allá de la tragedia antigua... se presenta el

yo —el yo metafísico, no el yo psicológico, individual, empírico-que se experimenta en el fondo como espejo irresistible y ciego de la voluntad de vivir. Eso tiende con todas sus fuerzas, sin tender sin embargo a nada, y eso sufre en la medida en que ningún objeto puede colmar ese ardor que devora. Eso se conoce inmediatamente, fuera de todo tiempo y fuera de todo espacio. Eso no tiene ni comienzo ni fin; eso es la enfermedad hasta la muerte (Bangur, pág. 209).

\section{Y San Manuel ha exclamado:}

Yo no puedo perder a mi pueblo para ganarme mi alma... Yo no podría soportar las tentaciones del desierto. Yo no podría llevar solo la cruz del nacimiento (856).

Sobre eso palpita la gris espuma de los días, que ha engañado a los filósofos hasta el punto de hacerles tomar la apariencia por el ser, y de inspirarles esa carencia de sentido: la filosofía de la historia (Bangur, pág. 210).

Y es que la nivola cuyo sentido, o uno de sus sentidos, pretendemos alcanzar, se incluye, cual veremos en ese aspecto de la historia que la trasciende -intra o metahistoria- - para ofrecernos según Unamuno, su visión de este género:

Bien sé que en lo que se cuenta en el relato, se quiere novelesco y la novela es la más íntima historia, la más verdadera, por lo que no me explico que haya quien se indigne de que se llame novela al Evangelio, lo que es elevarlo en realidad sobre un cronicón cualquiera, bien sé que en lo que se cuenta en este relato no pasa nada; mas espero que sea porque en ello todo se queda, como se quedan los lagos y las montañas y las santas almas sencillas, asentadas más allá de la fe y de la desesperación, que en ellos, en los lagos y las montañas, fuera de la historia, en divina novela se cobijara (878-879).

El autor, ya que como tal se presentifica al final del relato, ha reflejado varias miradas a través de sus narradores, y la de Don Manuel y Lázaro trascienden la mirada exterior del mundo, su representación. Y descubre que la forma de espacio y tiempo provienen del interior de la conciencia despierta, del sujeto de conocimiento cuyo cuerpo individual - podríamos decir encarnado- es voluntad .

La unidad del espacio la proporciona el cuerpo como matriz de experiencias; la continuidad en el tiempo, el hilo de la memoria y la esperanza (Cerezo 1996, pág. 513). 
Ese mismo cuerpo visto desde el exterior es representación fenoménica; cubierta o embellecida por el velo maya. Mas todo cuerpo exterior es, a su vez, en su profunda interioridad, voluntad:

Existir para otro es ser representado; existir para sí es querer-voluntad (Schopenhauer, pág. 172).

Y en esa tensión lucha el ser, se debate y se pregunta por el sentido de una existencia abocada a la muerte y a la nada. Y es paradójico que la expresión de Calderón de la Barca en La vida es sueño se entroque en ambos filósofos:

Llegué a casa y me puse a rezar y al llegar a aquello de ruega por nosotros pecadores, ahora y en la hora de nuestra muerte, una voz íntima me dijo: ¿pecadores? ¿pecadores nosotros? ¿y cuál es nuestro pecado, Padre?

- ¿Cuál? - me respondió - ya lo dijo un gran doctor de la Iglesia... ya lo dijo el gran doctor de La vida es sueño, ya lo dijo: "el delito mayor del hombre es haber nacido". Ese es, hija, nuestro pecado: el de haber nacido (871).

Y en ello, podría integrarse la afirmación de María Zambrano.

Pues que el nacer es proyectarse en un ser que aspira a la posesión del universo. Si no hubiera esta forma de posesión inicial no sería el peor delito el haber nacido y seríamos inocentes. La posesión que está ya al principio es el delito, el robo. Anaximandro vio claro cuando halló la injusticia del ser, injusticia transitoria, porque todo ser es efímero (Zambrano 1989, pág. 17).

$Y$ es que el centro trágico tanto en Schopenhauer como en Unamuno se halla en ese sentido del nacimiento.

Es un hecho notabilísimo y muy digno de atención que el objeto de toda la alta poesía sea representación del lado horrible de la naturaleza humana, el dolor sin nombre, los tormentos de los hombres, el triunfo de la perversidad, la irónica dominación del azar, la irremediable caída del justo y del inocente. Este es un signo notable de la constitución del mundo y de la existencia... ¿No vemos en la tragedia a los seres más nobles, después de largos combates y sufrimientos, renunciar para siempre a los propósitos que perseguían hasta entonces con tanta violencia o apartarse de todos los goces de la vida voluntariamente, con súbito? Así con el príncipe de Calderón; Margarita en Fausto; Hamlet a quien su querido Horacio seguiría con mucho gusto, pero que le promete quedarse y respirar aún algún tiempo en un mundo tan rudo y lleno de dolores, para narrar la suerte de Hamlet y purificar su memoria; lo mismo que la Virgen de Orleans, que la desposada de Messina; todos mueren purificados por los sufrimientos; es decir después que ha muerto en ellos la voluntad de vivir.

El verdadero sentido de la tragedia es esta mirada profunda; que las faltas expiadas por el héroe no son las faltas de él, sino las faltas hereditarias, es decir, el crimen mismo de existir:

...pues el delito mayor

del hombre es haber nacido... (Schopenhauer 1991, pág. 147).

$\mathrm{Y}$ ese nacimiento parece fundirse/unirse a la experiencia del dolor, que sobrevuela todo el trasfondo de la nivola unamuniana, en vacíos, en esos tedios que el sacerdote ha descubierto cual sinsentido de la vida. 
He asistido a bien morir a padres aldeanos, ignorantes, analfabetos que apenas si habían salido de la aldea, y he podido saber de sus labios, y cuando no adivinarlo, la verdadera causa de su enfermedad de muerte, $y$ he podido mirar, allí, a la cabecera de su lecho de muerte, toda negrura de la sima del tedio de vivir (866).

Ese sentido del tedio, textura de muerte, parece fluir a través de todo el proceso del sacerdote que adquiere por una parte, unos rasgos quijotescos y por otra, crísticos. En determinados instantes de la obra resuenan las palabras evangélicas de la pasión y el abandono: “Dios mío! ¡Dios mío! ¿Por qué me has abandonado?" Y esa voz tiene su eco en Blasillo, el tonto o el bienaventurado que sugiere a su vez la imposibilidad de la "razón suficiente" para explicar el sufrimiento, ya que él está desprovisto de razón —que no de corazón—, o se sitúa mas allá de ella. Y podría, como ha visto algún crítico, suponer una visión pascaliana - de ahí su nombre-, esa filosofía que tan hondas interrelaciones supone con la de Schopenhauer. Y ese eco del abandono se irá repitiendo como síncopa musical a lo largo de todo el relato.

Mas sería oportuno en otro aspecto y siguiendo la hilatura constructiva de Schopenhauer, en su parte tercera de El mundo como voluntad y representación en la que refleja una nueva visión de la representación, tras el ser que ha descubierto la voluntad, cercana a la idea platónica, independientemente de todo principio de razón. La conciencia maravillada y en búsqueda de lo bello y lo sublime, sale de ella misma, se distiende para dejar fluir el reflejo de la voluntad objetivada, encuentro entre objeto y sujeto y superación de la dispersión - surge la Idea tan cercana a la expresada por Platón en su dialogo Fedón. Pues que toda contemplación supone una reminiscencia y una llamada hacia la perfección según el filosofo griego. Mas en Schopenhauer la idea no es el alma, el mundo, Dios... sino una idea especifica e inmutable; algo que le separa, en esta visión, de Unamuno y es que para el filósofo español "su egoísmo, el del filósofo alemán, le impidió sentir a Dios". Y más acá de la existencia "su falta de sentido social e histórico, el no sentir a la Humanidad como una persona también aunque colectiva, su egoísmo, en fin, le impidió individualizar y personalizar la voluntad y total colectiva. La voluntad del universo" (Cerezo, pág 404 y 534).

Para Schopenhauer cada individualidad humana "expresa parcialmente el contenido total de la idea", mas ello implica un horizonte trágico del ser engarzado entre dos fuerzas: la de la fusión del amor hacia el mundo y el inexorable alejamiento a través de la muerte.

Hallamos, en el camino de este filósofo, que la voluntad implica al propio tiempo su renuncia; pues que el ser, aterrorizado ante la amplitud de la voluntad, parece ser llamado a su aniquilamiento. La voluntad se afirma y al conocerse se niega. Algo que ya parece anunciar la lucha entre Eros y Thanatros de Freud. Y en otro aspecto a Nietzsche y su visión del nihilismo: 
En términos del ser, la nada era impensable. La nada como tal apareció, no en la filosofía sino en la religión, como último fondo de donde saliera la realidad toda por un acto creador. Esta nada no pudo en realidad entrar a formar parte de la fillosofía que se ocupaba de las cosas creadas, de las cosas que son, que están dentro o bajo el ser. Sólo al hombre podía afectarle esta nada. Pero le afectó poco, en tanto que ente pensable y definible; le afectaría en su vida; en su agonía de criatura perdida en las tinieblas (Zambrano 1993, pág. 177).

Mas tras esa nada brota o fluye una dimensión nueva del hombre. Y más allá de las corrientes religiosas que Schopenhauer a primera vista rechaza y que hayan podido influir en su pensamiento, no podemos dejar de olvidar que la negación contiene una afirmación "a contrario sensu". Por una parte es una vía de serenidad, tan unida a la mística y al quietismo que han tenido hondo reflejo en San Juan de la Cruz y la guía espiritual de Miguel de Molinos. Y ese mismo sentido, en su faz de éxtasis oriental y de emoción ante la muerte y el dolor, revela una voluntad de vivir que anima al hombre en otra dimensión.

Y es que ningún filósofo, pese a que tantas veces lo ha pretendido, sobre todo en el pensamiento anterior a Schopenhauer —algo que no se refleja en la poesía- puede todo explicar, razonar..., pues la voluntad primordial, libre, todo potente e irracional, tiene un fondo misterioso. Ello lo hallamos en las doctrinas védicas, ese sagrado nihilismo apoyado en la misteriosa experiencia comunicativa, íntima del yo hacia el otro, para llegar a hacerle comprender esa casi invisible fusión con el todo, que asemeja lo uno, hasta la ruptura final. En la voluntad hay misterio, que no proviene del conocimiento ni tampoco es una revelación: "Podría suceder que todo aquello que nosotros no llegamos a saber, no fue sabido por persona y no fue de naturaleza a ser sabido, es decir no fue representable" (Schopenhauer 1992, pág. 129).

$\mathrm{Y}$, por otra parte, el ser no se halla en armonía, cuando su vida se traduce en esa continua lucha entre el deseo incesante y la ansiedad de la tensión en un trasfondo en el que aparece un sin sentido de la existencia en la que todo es sufrimiento. El hombre queda situado en una balanza en cuyos extremos fluyen la angustia y el tedio.

De ello se puede encontrar un eco en la historia de San Manuel:

Mi pobre padre, que murió cerca de los noventa años, se pasó la vida, según me confesó él mismo, torturado por la tentación del suicidio, que le venía no recordaba desde cuando, de nación, decía, defendiéndose de ella. Y esa defensa fue su vida. Para no sucumbir a tal tentación extremaba los cuidados por conservar la vida. ;Mi vida Lázaro! [exclama ante el hermano de Angela, el espíritu científico que menosprecia, en un principio, la aldea] es una especie de suicidio continuo, un combate contra el suicidio; pero que vivan ellos [refiriéndose al pueblo] que vivan los nuestros (867).

Para Schopenhauer fluyen dos aspectos que lejos de distanciarse confluyen. La piedad y el genio. La piedad es la superación del egoísmo, por la que forjamos, éticamente, una esencia a los seres que se revelan a través de ella. "El profundo 
dolor que nos hace sentir la muerte de un amigo, proviene del sentimiento de que en cada individuo hay algo indefinible, propio a él mismo y, como consecuencia, algo absolutamente irreparable" (Schopenhauer 1992, pág. 168). Y si el dolor reside en el fondo de cada vida, la piedad supone compartir el dolor del otro y procurar dulcificarlo. Trasfondo del amor y la ternura. Amarnos - dice Unamuno- "en espíritu, es compadecer y quien más compadece más ama..." Y el amor es la única medicina contra la muerte (Cerezo, pág. 456). Mas ello no supone una confusión con el otro, con su dolor, sino que es en la persona del otro que sufrimos, en la que hemos proyectado la nuestra: "su dolor deviene nuestro". Y metafísicamente sentimos que nuestro verdadero ser queda fuera de nuestro ser fenoménico, reside en un otro. Y ello supone, en cierta manera, una renuncia a la voluntad o una visión de la "voluntad hambrienta en la naturaleza, en la forma de lucha universal, de realización" (Cerezo, pág. 39).

La visión del genio para el filósofo alemán, supone el ser que abandona todo fin utilitario en su existencia; lo compara a la visión del Mont Blanc que eleva su cúspide serena por encima de las nubes; e importancia también adquiere la montaña en la nivola. El genio es el ser contemplativo y su grandeza "reside en su aptitud en abandonar todo interés personal para perseguir una finalidad objetiva". Se caracteriza por un excesum, lo que supone en este contexto una voluntad más fuerte. "Él siente pasiones más intensas que las de los otros, despreocupación de interés en su propio camino y, en general, de todos los cálculos que parece imponer toda prudencia" (Schopenhauer 1992, pág. 183).

Cierto sería que el genio, como el creador, se sitúa en los límites de la locura. Mas su diferencia con el loco reside en situarse por encima del principio de razón suficiente, mientras el loco se sitúa por debajo de él. Frente al genio, el niño tiene su inteligencia libre y fresca... mientras la sexualidad no adquiera su desarrollo... su inteligencia queda libre; y hay algo semejante al espíritu libre del que nos hablara Nietzsche. Mas esta libertad es de corta duración.

Como espejo de ello aparecen las últimas palabras de San Manuel a Angela, la primera narradora de los hechos. "Cuando me entierren, que sea en una caja hecha con aquellas seis tablas que tallé del viejo nogal, ipobrecillo!, a cuya sombra jugué de niño, cuando empezaba a soñar. ¡Y entonces sí que creía en la vida perdurable!. Es decir, me figuro ahora que creía entonces. Para un niño creer no es más que soñar. Y para un pueblo" (872). Algo hay, asimismo, en Blasillo de niño y de loco. El genio es el elegido, ese espíritu que se sitúa más allá de ese hombre ordinario, ese producto industrial que la naturaleza fabrica en orden de varios miles por día. La visión del hombre tecnificado por parte de Heidegger ya parece hallar su imagen precedente.

El sentido del éxito inmediato no supone una finalidad. Pues sería apartar al individuo de ese destino común al que parece ser llamado, dándole acceso hacia $L a$ Idea en su propia realización o en la promoción de una obra de arte que integra su 
visión. Y es que "la voluntad, esencia genérica de la vida, actúa a modo de impulso originario, que inspira y dirige al individuo más allá de las condiciones empíricas. ...En ese trasfondo de ideas subyace oscuramente el plantemiento unamuniano del 'secreto del yo' como símbolo dinámico de su ser 'No es tanto en el hacer cuanto en el querer donde has de buscar tu libertad" (Cerezo, pág. 87).

Casi proféticamente ya hallamos, en otro aspecto, ese temor de la tecnificación en los diálogos entre Don Manuel y Lázaro, que recoge la narradora.

—Él me hizo un hombre nuevo, un verdadero Lázaro, un resucitado -me decía-, él me dio fe

- ¿Fe? le interrumpía yo

- Śí, fe, fe en el consuelo de la vida, fe en el contento de la vida, él me curó de mi progresismo. Porque hay, Angela, dos hombres peligrosos y nocivos: los que convencidos de la vida de ultratumba, de la resurrección de la carne, atormentan como inquisidores que son a los demás para que, despreciando esta vida como transitoria, se ganen la otra; y los que no creyendo más que en ésta, esperan no sé qué de una sociedad futura...

Antes ya había exclamado: "¿Y no crees que del bienestar general surgirá más fuerte el tedio de la vida?"

Mas el genio es hombre contemplativo, y a través de esa visión contempladora - casi sagrada - es capaz más allá de su dolor, de su piedad, de recrear el mundo como arte. La belleza consuela, y a través de ella el hombre parece superar su caída, el dolor de su nacimiento, sus "infiernos" para acceder a un desligamiento sereno. Y algo de Plotino se espejea en esta contemplación; el pensador griego para quien todos los seres desean contemplar, cual hecho sucedáneo y consolador de una acción.

Absorbámonos y sumerjámonos en la contemplación de la naturaleza... sentiremos inmediatamente por ello que somos, por así decirlo, el soporte del mundo y de toda existencia objetiva, pues ésta no aparece ya sino a título correlativo de nuestra propia existencia. Abramos así toda la naturaleza hacia nosotros (Schopenhauer 1992, pág. 247).

La contemplación supone un privilegio de la visión inmediata y directa en la que no interviene ni el entendimiento discursivo ni la razón conceptual. Es como un reflejo semejante al del espejo en que el objeto se mira en el sujeto... el mundo deviene espectáculo. Estamos ante el fenómeno de esa creación artística alejada de todo cálculo, de todo interés... Pues el artista no tiene una conciencia in abstracto de intención, ni de finalidad de su obra; ella no es un concepto, sino una idea que se presenta a su espíritu... elabora inconscientemente, instintivamente.

Frente al fenómeno de concepción artística, la idea es intemporal, y el sujeto pura recepción; se libera de las cadenas de la voluntad en esa mirada desentrañada de la fuerza del deseo. Y el mundo, mirado así, se trasforma para Schopenhauer cual un texto abierto, no escrito y de autor abolido. Y entre las artes es la música la 
que ofrece, en un espacio más elevado, ese arte que existiría aunque el mundo no existiese; cifra misteriosa y mágica que nos llama a algo perdido, anterior a la escritura del mundo. Se sitúa como una ausencia ante la presencia; cual ese tiempo -olvido- anterior a la irreversibilidad.

La contemplación es consuelo "Yo encuentro —nos dice Schopenhauer en una de sus cartas- que la vista que se extiende desde la cima de una montaña contribuye hondamente a ofrecernos horizontes sobre el mundo. El mundo contemplado desde lo alto es un espectáculo tan fantástico y curioso que puede consolar a aquél que está asolado por las preocupaciones". Frente al dolor de la existencia de la lucha fluye la sensación de serenidad, de reposo y es aquél en que "cada uno es dichoso, cuando es todas las cosas; desgraciado cuando sólo es un individuo" (Schopenhauer 1992, pág. 161).

Aparece un centro o motivo, que se repite a lo largo de la nivola, que otorgará su armonía, cual es la presencia de la montaña y el lago. Por una parte simboliza esa voz que trasciende y que se eleva, y que para Angela es al inicio la imagen del sacerdote. Musical puesto que es canto: "Su canto, saliendo del templo, iba a quedarse dormido sobre el lago y al pie de la montaña" (853). Y otras veces su voz asemeja a esa firmeza de la montaña que recoge, a través de todo el coro popular, el testimonio de una voz unísona que parece fundirse en una creencia. " Creo en Dios Padre Todopoderoso, creador del cielo y de la tierra'... y no era un coro, sino una sola voz, una voz simple y unida, fundidas todas en una y haciendo como una montaña, cuya cumbre, perdida a veces en nubes, era Don Manuel". Y en otro significado el lago simboliza una pérdida, el reflejo de un deseo, la felicidad del pueblo que no era para él; "Y al llegar a lo de "creo en la resurrección de la carne y la vida perdurable', la voz de Don Manuel se zambullía, como en un lago, en la del pueblo todo, y era que él se callaba". Si el lago para Don Manuel es la contemplación del silencio, para Angela simboliza la música y la armonía que trasciende la imagen del sacerdote. "Y yo oía las campanas de la villa que se dice aquí que está sumergida en el lecho del lago - campanadas que se dice también se oyen en la noche de San Juan - y eran las de la villa sumergida en el lago espiritual de nuestro pueblo; oía la voz de nuestros muertos que en nosotros resucitaba en la comunión de los santos (853).

El lago como reflejo de la íntima identidad del pueblo y del misterio, y como intrahistoria o trasfondo del alma de todo el pueblo; y esa doble perspectiva, la de San Manuel y Angela, podría simbolizar

la intrahistoria y en la nivola representa la continuidad de vivos y muertos, las dos ciudades hermanas, la de su orilla y la que guarda su fondo, como partícipes de un mismo destino. Pero como todo símbolo es ambivalente, pues la quietud de estas aguas dormidas puede significar tanto el anegamiento de la conciencia en lo eterno inmutable como la disolución en la nada (Cerezo, pág. 717). 
Mas para la narradora tiene un eco también bíblico, casi renacedor semejante a "una caravana en marcha por el desierto, desfallecido el caudillo al acercarse al término de su carrera. Le tomarán en hombros los suyos para meter su cuerpo sin vida en la tierra de promisión".

El lago es el trasfondo entre las conversaciones de Lázaro y Manuel; una trascendencia misteriosa que parece reflejarse en las ruinas de la abadía cisterciense. Y no podía dejar de constatarse que el lago siempre va unido a la musicalidad -coro, voces, abadía... - y ya hemos señalado la visión que sobre ella entrañaba Schopenhauer. "Y creo que en el fondo del alma de nuestro Don Manuel hay también sumergida, ahogada, una villa y que alguna vez se oyen las campanadas".

Pero esa visión de la contemplación y la música se hace más honda cuando escucha el canto de una zagala, "una cabrera que enhiesta sobre un picacho de la falda de la montaña, a la vista del lago estaba cantando con una voz más fresca que las aguas de éste". Ante lo que el sacerdote siente esa sensación de un tiempo preservado, de un eterno olvido. "Mira: parece como si se hubiera acabado el tiempo, como si esa zagala hubiese estado siempre, y como está, y cantando como está y como si hubiera de seguir estando así siempre, como estuvo cuando empezó mi conciencia, como estará cuando se me acabe. Esta zagala forma parte de las rocas, las nubes, los árboles, las aguas, de la naturaleza y no de la historia." Unamuno se funde con Schopenhauer en esa eternidad del momento, de la contemplación de la naturaleza, perenne como la música del canto, fuente de una historia que podría parecer pasajera. Es en ello que Don Manuel halla el hondo sentido de lo puro, de lo intacto. “Has visto Lázaro misterio mayor que el de la nieve cayendo en el lago y muriendo en él mientras cubre con su toca a la montaña (868).

"El desarrollo del argumento - piensa Wyers- es también el desarrollo de esta imagen central que funda al cura, al lago, a la montaña y a todos los habitantes de la villa, vivos y muertos, en una única entidad, cuyos diversos componentes se copian y reflejan unos a otros" (Cerezo, pág. 716). Y en efecto el lago, cual espejo de la montaña en sus diversos matices irá subrayando las tonalidades y motivos de la nivola.

Si Don Manuel parece fundirse en la naturaleza "había en sus ojos toda la hondura azul de nuestro lago" y por otra parte queda como un reflejo en la tradición evangélica y quijotesca de Unamuno; de Cristo y el sentido misterioso del abandono del Padre, y el eco repetitivo de las palabras de la pasión así lo atestiguan. Y en su entraña quijotesca, su propio aspecto "alto, delgado y erguido", las obras citadas El Quijote y el Bertoldo, y esa lucha que amplía su horizonte...

La naturaleza queda, pues, replegada en la montaña llamada también la Peña del Buitre "con clara alusión al mito de Prometeo, el titán que escala los cielos para robar el fuego sagrado y Zeus le hizo expiar su falta exponiéndolo al pico voraz de un buitre que le devoraba las entrañas sin reposo" (Cerezo, pág. 716). Mas el buitre 
es el ave que devora los muertos, en su otra faz; quizás en ello la montaña simbolice ese sentido de muerte, de pérdida tan presente en la obra. Y el lago, con su ciudad medieval sumergida, puede significar el misterio de la entraña perdida, pero en su quietud el lago también es muerte; o también contemplación, tiempo intemporal en la vida, la vida representada en el río que lo atraviesa - alusión posible a los versos de Jorge Manrique - para desembocar en el mar, horizonte ilimitado o sabor amargo de un fenecer. "Aquí se remansa el río en el lago, para luego, bajando a la meseta, precipitarse en cascadas, saltos y torrenteras por las hoces y encañadas, junto a la ciudad, y así remansa la vida, aquí en la aldea. Pero la tentación del suicidio es mayor aquí, junto al remanso que espesa de noche las estrellas que no junto a las cascadas que dan miedo" (868)

Mas también supone la plegaria, quizás aquella en la que San Manuel no cree y que la naturaleza le hace creer.

Una noche de plenilunio.;.. volvían de la aldea por la orilla del lago, a cuyo sobrehaz rizaba entonces la brisa montañesa y en el rizo cabilleaban las caras de la luna llena, y Don Manuel le dijo a Lázaro:

- iMira el agua, está rezando la letanía y ahora dice: Ianua caeli, ora pro nobis, puerta del cielo, ruega por nosotros! (868)

San Manuel Bueno, mártir nos ha parecido una de las obras más logradas de uno de los pensadores más profundos de la literatura española. El pretender hallar las huellas de uno de los iniciadores del pensamiento moderno cual es Schopenhauer, supone una faceta profunda, aunque no única en la filosofía unamuniana... pues Kierkegaard, Nietzsche... y tantos otros se hacen presentes o quizás, incluso, con mayor intensidad. Mas la faz infernal de la existencia tiene aspectos que irradian en un mismo reflejo en ambos pensadores. Y es que el sabio, como afirma Aristóteles en su Ética a Nicómano, "busca la ausencia del dolor y no el placer". Pero la voluntad de Schopenhauer implica superar esa primera representación del mundo, su ensoñación, integrar sus ínferos, no le está permitida la elusión del infierno a quien pretenda explorar la vida humana. Mas conocer la vida obliga a explorar la totalidad de la vida, a no retroceder ante nada.

Y esto exige, exigirá cada vez más inexorablemente de la inteligencia, una inteligencia, una inocencia que nunca tuvo y una renuncia nueva: la renuncia si no a su infierno a su laberinto propio. La conquista de una simplicidad que le acerque a la luz original, a la luz que no le impone la claridad, a no hacer de su claridad una estructura como hizo Descartes. Y tras él, todos los demás, excepto Nietzsche - y podemos integrar a Schopenhauer-Kierkegaard y, anteriormente Pascal, en quienes alumbra una desigual claridad más evocadora de la lámpara de aceite indecisa, alada y vacilante que la uniforme luz de la conciencia y de la razón pura (Zambrano 1993, pág. 87).

La visión de los ínferos en Don Manuel le ha llevado a esa piedad, esa conmiseración hacia los otros, hacia el pueblo a quien cree o sueña más feliz en su sueño- 
representación que en la realidad-voluntad. Esa piedad, conmiseración que es "el hecho asombroso y lleno de misterios en virtud del cual vemos borrarse la línea periférica que a los ojos de la razón separa totalmente un ser de otro ser, y convertirse el "no yo" en cierto modo en el yo... es producto espontáneo, inmediato, inalienable de la naturaleza; resiste a todas las pruebas y se manifiesta a todos los pueblos y países" (Schopenhauer 1991, pág. 163).

La voz de Don Manuel ha integrado esta vía, se ha trascendido en naturaleza y en las de Angela y Lázaro, los demás narradores de la novela - y a través de ellos llega al autor. Y su voz se transfiere en sueño - trágico para él- hacia el pueblo. "La voz de Don Manuel se zambullía como en un lago, en la del pueblo todo... [voz-visión] se llevaba las miradas de todos ellos y tras ellos los corazones, y él, al mirar, nos parecía, traspasando la carne como cristal, mirarnos al corazón. Todos le queríamos, pero sobre todo los niños [y voz-olfato] el pueblo se sentía lleno y embriagado de su aroma".

Refleja "ese género del amor que no tropezará con la resistencia de lo amado; un amor, en el cual, entender o querer se acreciente con el amor mismo y lleguen a ser la misma cosa, entender y amar, amar y entender" (Zambrano 1989, pág. 31).

Unamuno representa en el pensamiento hispano moderno, la razón agónica; esa lucha entre sueño — con huellas de inmortalidad-y realidad en la que el hombre se ahonda en las entrañas trágicas de la existencia. Ortega y Gasset supuso la razón vital. María Zambrano y su razón poética logran conciliar el sueño y la vida; pues el sueño despierta, es un despertar, continuamente a través de la existencia; o mejor dicho debe despertarse...

Y en la estructura casi invisible de toda esta nivola se halla esa voz-coro; vozcanto, voz-música... Y es que "La música no expresa nunca el fenómeno, sino únicamente la esencia íntima, el "en sî" de todo fenómeno, en una palabra la voluntad misma. Por eso no expresa la alegría especial o definida, tales o cuales tristezas, tal dolor, tal espanto, tal arrebato, tal placer, tal sosiego de espíritu, sino la misma alegría, la tristeza, el dolor, el espanto, los arrebatos, el placer, el sosiego del alma. No expresa más que la esencia abstracta y general, fuera de todo motivo y de toda circunstancia. Y, sin embargo, sabemos comprenderla perfectamente en esa quinta esencia abstracta" (Schopenhauer 1992, pág, 150).

\section{REFERENCIAS BIBLIOGRAFICAS}

BANGUR, Wanda. 1984. "Schopenhauer" en Historia de la Filosofía, dirigida por François Chatelet, Madrid, Espasa-Calpe.

CEREZO GALAN, Pedro. 1996. Las máscaras de lo trágico (Filosofía y tragedia en Miguel de Unamuno), Madrid, Ed. Trotta. 
SCHOPENHAUER, Arthur. 1991. El amor, las mujeres y la muerte, Madrid, Edaf S.A.

- 1992. El mundo como voluntad y representación, México, Ed. Porrúa.

UNAMUNO, Miguel de. 1986. San Manuel Bueno, mártir, en Obras Selectas, Madrid, Biblioteca Nueva.

ZAMBRANO, María. 1989. Delirio y destino, Madrid, Mondadori.

- 1993. El hombre y lo divino, Madrid, Siruela. 